\title{
Survey on Context-Aware Pervasive Learning Environments
}

\author{
doi:10.3991/ijim.v3i1.680 \\ T.H. Laine ${ }^{1}$ and M. Joy ${ }^{2}$ \\ ${ }^{1}$ University of Joensuu, Joensuu, Finland \\ 2 Warwick University, Coventry, UK
}

\begin{abstract}
Context-aware pervasive learning environments consist of interconnected, embedded computing devices such as portable computers, wireless sensors, auxiliary input/output devices and servers. Until this study there has been no survey that has evaluated and presented information regarding these environments. In this paper, we conducted a survey to identify the commonly used technologies, methods and models behind these systems, and evaluated the role of mobile devices in the reviewed papers. As a result, we made five observations: (i) RFID was the most common sensor technology; (ii) several learning models were suggested, but none was validated properly; (iii) client-server architectures are prevalent in the systems and mobile devices were used most commonly to represent information; (iv) most of the systems supported multiple simultaneous users, but few facilitated virtual communication; and (v) possible roles for physical environments in pervasive learning systems are: contexts for learning, content for learning, and system resources. Evidence indicates that suitable learning models have yet to be validated, and that more roles of mobile devices could be emphasised.
\end{abstract}

Index Terms - context-aware, literature survey, mobile learning, pervasive learning environment.

\section{INTRODUCTION}

Mobile learning, or m-learning, has become popular and is currently being intensively researched. In this paper we consider m-learning to refer specifically to learning facilitated by mobile devices such as PDAs and mobile phones. The primary aim of m-learning is to provide the users with a learning environment which is not restricted to a specific location or time. Compared to a traditional classroom setting, m-learning increases the mobility of a learner, allowing him/her to learn while sitting in a bus, for example. Furthermore, networked mobile devices allow learners to perform co-operative learning tasks in a group.

Pervasive learning is the latest trend in harnessing the technology to support learning. In this form of learning, the mediator is a pervasive computing environment which consists of interconnected, embedded computing devices such as portable computers, wireless sensors, auxiliary input/output devices and servers. One could therefore consider pervasive learning as an extension to m-learning where the roles of the intelligent environment and of the context are emphasised. The physical environment is central as it provides salient resources for learning. According to [15], a pervasive learning environment is a setting in which students can become totally immersed in the learning process. They further note that pervasive computing is an immersive experience which mediates between the learner's mental (e.g. needs, preferences, prior knowledge), physical (e.g. objects, other learners) and virtual (e.g. content accessible with mobile devices, artefacts) context. The intersection of these contexts is referred to as pervasive learning environment ([15]). Reference [14] regard a pervasive learning environment as a collection of mobile users, mobile services, mobile devices, contexts and policies, while [12] state that in pervasive learning, computers can obtain information about the context of learning from the learning environment in which embedded small devices, such as sensors, pads and badges, communicate together. Common to these definitions is the interplay of intelligent technology and context in which the learner is situated (i.e. context-awareness). Other terms used to describe pervasive computing include situated computing, ubiquitous computing, embedded computing, ambient intelligence, and everyware. In this paper, pervasive learning environments are based on environments with embedded intelligence in the form of sensors, tags and interaction devices.

There has been research conducted on building and evaluating pervasive learning environments, however no survey has yet evaluated these environments. Such information is necessary not only for avoiding reinventing the wheel, but also for understanding the current state-ofthe-art in this area. By recognising the commonly used technologies, methods and models, we can design and build pervasive learning systems more effectively. Our intention is to provide an overview of what kind of pervasive learning environments have been developed, how they were built, what are the sensor technologies used in these systems to make them context-aware, what learning models are suggested for these environments, and what are the roles of mobile devices. By reviewing existing work, we seek to build a solid ground for further research on how different learning models can be efficiently utilised in pervasive learning environments and what are the critical features of such an environment. The role of mobile devices is an important factor from the perspective of wider work which aims to design and implement a flexible pervasive mobile learning system. This work also includes establishing and recognising the best learning models for such system.

The paper is organised as follows. We first define the methodology used in the survey and continue by describing the observations resulted from the analysis of 
the literature. Finally, we conclude by discussing implications of the results and concluding the findings.

\section{METHOD}

This section presents the research questions and designs of data collection, evaluation and analysis.

\section{A. Research Questions}

In this survey we focused on articles presenting research outcomes that included a design, implementation, evaluation or test of a context-aware pervasive learning environment. We established a set of questions to be answered with the information extracted from the literature. These questions and their purpose are presented in Table I.

TABLE I.

RESEARCH QUESTIONS AND THEIR PURPOSE

\begin{tabular}{|c|c|}
\hline Question & Purpose \\
\hline \begin{tabular}{|l|} 
1. What are the currently \\
existing context-aware \\
pervasiver rearning \\
environments \\
are they built?
\end{tabular} & $\begin{array}{l}\text { We seek to discover the state-of-the-art in } \\
\text { the field of context-aware pervasive } \\
\text { learning environments. The survey is done } \\
\text { from a technical perspective, emphasising } \\
\text { particularly technologies for smart } \\
\text { environment (e.g. sensors). }\end{array}$ \\
\hline 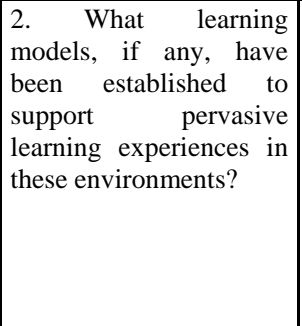 & $\begin{array}{l}\text { We consider this question particularly } \\
\text { relevant because if there are no learning } \\
\text { models established or validated in the } \\
\text { previous work, we will have a rationale to } \\
\text { conduct further research on the learning } \\
\text { models in this field. If previous work } \\
\text { supports particular learning models for } \\
\text { pervasive learning, those can be used } \\
\text { together with newly established models in } \\
\text { the future work. }\end{array}$ \\
\hline \begin{tabular}{|l|} 
3. What is the role of \\
mobile devices in \\
existing pervasive \\
learning environments?
\end{tabular} & $\begin{array}{l}\text { This question is intended to find out how } \\
\text { mobile devices have been harnessed in } \\
\text { existing pervasive learning environments. } \\
\text { The results of this question will be used to } \\
\text { invent and combine ways to utilise mobile } \\
\text { devices in pervasive learning. }\end{array}$ \\
\hline
\end{tabular}

\section{B. Data Collection}

In order to collect the data in a reliable and reproducible manner, we devised a set of rules for paper inclusion. The established inclusion rules were as follows.

a) The work describes a design, implementation, analysis or test of a pervasive learning environment or system.

b) The presented environment/system uses sensors or other technologies for smart environments to enable context-awareness; having people walking around with mobile devices connected to a wireless network was not enough as it is merely m-learning.

c) The work was presented in one of the following forums: IEEE International Conference on Pervasive Services, IEEE International Conference on Pervasive Computing and Communications, European Conference on Ambient Intelligence, International Conference on Mobile and Ubiquitous Systems, IEEE International Workshop on Wireless and Mobile Technologies in Education (WMTE \& WMUTE), Pervasive E-Learning Workshop, Pervasive Computing Education Workshop, Pervasive Learning Workshop. d) Data from one work does not overlap data from another work. In the case that two or more papers present the same system, the most recent or more comprehensive one was selected.

e) If the study does not present the design, implementation, evaluation or test of a pervasive learning environment, it must discuss the suitability of learning models and styles to an existing pervasive learning environment.

All works that failed to meet these rules were excluded. After establishing the inclusion rules, we performed the data collection in two phases. In the first phase titles and abstracts of articles presented in the given forums were read. If the title of an article did not seem relevant (e.g. the field was completely different), the abstract was not read. If the article showed relevance based on the title and the abstract, it was selected to the second phase. In total 35 papers were evaluated suitable as a result of the first phase.

In the second phase, the abstract and the introductions were read, and based on that information part of the papers were excluded as they did not meet the inclusion rules. After the second phase the number of relevant papers was decreased to 18 . We recognise that this is not a comprehensive survey from the paper point of view. However, the purpose of this paper is not to be a comprehensive literature review, but rather a directed probe into pervasive computing, learning and technologies.

\section{Data Evaluation}

After the main body of the papers was collected, we proceeded to read through the remaining papers in order perform a deeper analysis of the data and extract relevant information. For this purpose, we established a set of questions to be answered with that information. The questions are based on the research questions and they are presented in table II.

TABLE II.

DETAILED RESEARCH QUESTIONS

\begin{tabular}{|l|}
\hline \multicolumn{1}{|c|}{ Question } \\
\hline $\begin{array}{l}\text { Q-A0: What are the description and purpose of the } \\
\text { system/environment? }\end{array}$ \\
\hline $\begin{array}{l}\text { Q-A1: Is it based on a client/server approach? If not, what is it based } \\
\text { on? }\end{array}$ \\
\hline Q-A2: What is the hardware/software platform of the system? \\
\hline Q-A3: What is the programming language used in development? \\
\hline Q-A4: What kind of sensors are used and how? \\
\hline Q-A5: What is the role of the physical environment in the system? \\
\hline Q-A6: Is it a multi-user system? \\
\hline Q-B0: Are learning models discussed? \\
\hline Q-B0a: If yes, what are the suggested learning models? \\
\hline Q-B0b: How the suggested models have been validated? \\
\hline Q-B1: What learning activities does the system support? \\
\hline Q-C0: What is the role of mobile devices in the system? \\
\hline
\end{tabular}

In these questions $\mathrm{A}, \mathrm{B}$ and $\mathrm{C}$ refer to the research questions 1,2 , and 3 , respectively. The question Q-B0 has two sequential questions, namely Q-B0a and Q-B0b, which are only answered if the Q-B0 has a positive answer. We could not extract answers to all these 
questions from every paper, but majority of the papers had sufficient information available. During the evaluation process we excluded 4 papers as deeper analysis showed that they did not meet the inclusion rules, reducing the number of included papers to 14 . However, as one of the papers presents 2 different systems, the total number of relevant works was 15 . The observations based on the information extracted from these papers are presented in the following section. Papers that were part of the survey but are not explicitly referred to elsewhere in this article are: [1], [4], [11] and [16].

\section{OBSERVATIONS}

After the data evaluation, we performed a deeper analysis on the extracted information. As the result, a set of observations was established. These are presented in table III and in the following sections we present each observation in detail. The questions presented in table II are linked to the observations with the question codes in parentheses.

TABLE III.

OBSERVATIONS ON CONTEXT-AWARE PERVASIVE LEARNING ENVIRONMENTS

\begin{tabular}{|l|l|}
\hline Observation 1 & $\begin{array}{l}\text { RFID (Radio Frequency IDentification) is the most } \\
\text { prevalent sensor technology used in pervasive } \\
\text { learning environments. (Q-A4) }\end{array}$ \\
\hline Observation 2 & $\begin{array}{l}\text { There are several learning models that are suitable } \\
\text { for different learning activities in pervasive learning } \\
\text { environments, but none of them was validated } \\
\text { properly (Q-B0, Q-B0a, Q-B0b, Q-B1) }\end{array}$ \\
\hline Observation 3 & $\begin{array}{l}\text { The vast majority of the systems are based on a } \\
\text { client-server architecture and most of them utilize } \\
\text { mobile devices in various ways; content } \\
\text { representation tool is the most common role for } \\
\text { mobile devices. (QA-1, QA-2, QA-3, Q-C0) }\end{array}$ \\
\hline Observation 4 & $\begin{array}{l}\text { The majority of the pervasive learning environments } \\
\text { support multiple simultaneous users, but only a small } \\
\text { number support virtual communication among the } \\
\text { users. (QA-6) }\end{array}$ \\
\hline Observation 5 & $\begin{array}{l}\text { Currently established roles for the physical } \\
\text { environment in pervasive learning systems are: } \\
\text { context for learning, content for learning, and system } \\
\text { resource. (QA-5) }\end{array}$ \\
\hline
\end{tabular}

\section{A. Observation 1}

From the reviewed works, the most commonly used sensor technology was RFID (Radio Frequency IDentification) as 9 out of 15 works mentioned it explicitly. The second most popular sensor technology was GPS, scoring 4 hits in total. Other explicitly mentioned sensors were light sensors, moisture sensors, wired trigger sensors, water flow sensors, piezoelectric "object usage" sensors, force sensors, temperature sensors, humidity sensors, infra-red distance sensors, motion sensors, touch sensors, cameras, 3D accelerometers and microphones. Two works did not explain what kind of sensors are used as they merely presented the possibility of using sensor technologies in the respective systems. From the 13 works that mentioned some sensors being used, 7 utilized more than 1 sensor type.

RFID has been successfully used for sensing nearby persons ([3]), physical resources ([3], [2]), locations of the user or objects ([12], [3], [2]), and user's actions ([2]). In addition to presenting a pervasive learning environment,
[13] mentioned two ambitious ongoing projects in Japan, namely food traceability and location-aware computing. The goal of the former project is to attach RFID tags onto all food products, thus increasing the visibility of the food production chains. The latter project aims to tag all places in Japan's national infrastructure, thus supporting efficient transportation, sightseeing and also pervasive learning. Most of the pervasive learning applications that utilised RFID technology used RFID reader embedded or attached (via Bluetooth or by using extension slots) to mobile devices to read the tag information. This might be an indication that RFID is likely to become the next big thing in mobile wireless near-field communication just like Bluetooth did a few years back.

\section{B. Observation 2}

Out of 15 works only 7 discussed learning models and most of them did not explicitly suggest their suitability. However, we were able to extract the learning model types supported in each system by carefully analysing the descriptions of system functionalities. As a result, we devised a list of learning models that could be used in pervasive learning environments. Many systems supported more than one of these models simultaneously, e.g. a system could be both group-based and problem-based. Table IV presents the extracted learning models and examples how they were used.

Reference [10] suggests the most suitable learning models for pervasive learning are on-demand learning, hands-on or minds-on learning, and authentic learning. They further divide authentic learning into action, situated, incidental and experimental learning. The authors particularly emphasize the effectiveness of authentic, contextual learning for learning a foreign language. It is clear, however, that authentic learning is suitable for any kind of learning need where environment and context are major factors.

TABLE IV.

LEARNING Models IN PERVASIVE LEARNING ENVIRONMENTS

\begin{tabular}{|l|l|}
\hline Learning model & \multicolumn{1}{|c|}{ Example } \\
\hline $\begin{array}{l}\text { Group-based } \\
\text { learning }\end{array}$ & $\begin{array}{l}\text { Reference [5] proposes a system which utilizes an } \\
\text { RFID-enhanced interactive sensor board for } \\
\text { museums. The idea is that when an object is placed } \\
\text { on the sensor board, a projected image on the board } \\
\text { shows more information about that object. The } \\
\text { board is able to recognise multiple objects } \\
\text { simultaneously, thus a group of learners can } \\
\text { communicate and learn at the same time. }\end{array}$ \\
\hline Individual & $\begin{array}{l}\text { Reference [8] presents a system in which children } \\
\text { gather information pertaining to a range of reptiles, } \\
\text { small mammals, insects, fish and birds both within } \\
\text { indoor and outdoor environments. Camera and 2D } \\
\text { bar codes are used to collect the information. The } \\
\text { children perform the activities independently and } \\
\text { communication between the users is not supported } \\
\text { by the system. Naturally, ad-hoc face-to-face } \\
\text { communication may occur, but learning is mostly } \\
\text { individual. }\end{array}$ \\
\hline Microlearning & $\begin{array}{l}\text { Reference [2] constructed a pervasive environment } \\
\text { for learning a foreign language according to the } \\
\text { model of microlearning, in which users are } \\
\text { continually given small chunks of knowledge. The } \\
\text { goal of the system is to teach vocabulary through } \\
\text { the usage of responsive everyday objects in a } \\
\text { household. When a learner interacts with an object, } \\
\text { the vocabulary related to it is played back as sound. }\end{array}$ \\
\hline
\end{tabular}




\begin{tabular}{|c|c|}
\hline $\begin{array}{l}\text { Authentic } \\
\text { learning }\end{array}$ & $\begin{array}{l}\text { Reference [10] proposes two different systems; } \\
\text { JAPELAS for learning polite Japanese expressions } \\
\text { through situations, and TANGO for learning } \\
\text { vocabulary about the surrounding objects. } \\
\text { According to the authors, both of these system are } \\
\text { particularly well suited for authentic learning as } \\
\text { language skills are best acquired in a real-world } \\
\text { environment. } \\
\text { The same authors have created the JAMIOLAS } \\
\text { pervasive learning environment ([12]), which } \\
\text { allows users to learn Japanese mimicry and } \\
\text { onomatopoeic expressions through authentic } \\
\text { situations. For example, when a user goes out and it } \\
\text { rains, the system tells the user onomatopoeia for } \\
\text { raining. The authors explicitly refer to this learning } \\
\text { activity as authentic learning. }\end{array}$ \\
\hline $\begin{array}{l}\text { Learning by } \\
\text { playing }\end{array}$ & $\begin{array}{l}\text { The pervasive learning environment presented in } \\
\text { [7] consists of a set of RFID- and sensor-enhanced } \\
\text { toys and a mobile device. In the "Knight's Castle", } \\
\text { the toy characters respond to children's actions by, } \\
\text { for example, telling a historical story or singing a } \\
\text { song. This system is a good example on how a } \\
\text { pervasive learning environment can be used in a } \\
\text { playful manner to educate children. }\end{array}$ \\
\hline $\begin{array}{l}\text { On-demand } \\
\text { learning }\end{array}$ & $\begin{array}{l}\text { Reference [9] present a pervasive learning system } \\
\text { (LORAMS) in which mobile videos and RFID- } \\
\text { tagged objects are used to record and share learning } \\
\text { experiences. There are two types of user role in the } \\
\text { system: movie provider and movie watcher. In the } \\
\text { latter role, users retrieve movies from the system } \\
\text { according to the context, so the learning material is } \\
\text { acquired in an on-demand basis, thus we can refer } \\
\text { the learning activity of the second user role as on- } \\
\text { demand learning. }\end{array}$ \\
\hline $\begin{array}{l}\text { Hands-on and } \\
\text { Minds-on } \\
\text { learning }\end{array}$ & $\begin{array}{l}\text { The pervasive learning environment (LORAMS) } \\
\text { presented in [9] supports learning by hands-on } \\
\text { experience (see "On-demand learning"). The } \\
\text { motivation for the system was to provide a tool to } \\
\text { record a learner's experience and share it later with } \\
\text { other learners. Hands-on activities are particularly } \\
\text { useful here, as after recording, they can be easily } \\
\text { imitated by other learners. }\end{array}$ \\
\hline $\begin{array}{l}\text { Problem-based } \\
\text { learning }\end{array}$ & $\begin{array}{l}\text { Reference [3] describes a pervasive learning system } \\
\text { for a university laboratory in which learners are } \\
\text { provided with a set of learning activities to } \\
\text { perform. The objects in the lab are equipped with } \\
\text { RFID tags so the system is aware what the users are } \\
\text { doing at any given moment, and can therefore } \\
\text { monitor the progress of the learning activities. } \\
\text { Learning activities are represented as complex } \\
\text { problems to be solved, hence problem-based } \\
\text { learning. }\end{array}$ \\
\hline
\end{tabular}

Despite several learning models being presented in the papers, few were tested or validated. Microlearning was tested by [2] by running a non-stop scenario for several weeks. Participants in the test were optimistic about the possible use of technology and they showed increased level of knowledge of their foreign language vocabulary. However, as the scenario was executed only for two test subjects, this result does not yet validate the usage of microlearning in sensor-enhanced pervasive learning environment, but neither does it disprove the positive effect of the technology on learning. The system presented by [8] (independent learning) was validated by two test settings; an initial user study with a small group of children, and an investigation of overall performance of the system. The results of the former test suggested that the children enjoyed using the system and the overall feedback was positive. The school staff members were also supportive towards the usage of the system. The performance test concentrated on how the process of capturing an image and awaiting a response affected the usability of the system. The time of the process varied from 6 to 26 seconds, depending on the status of the GPRS connection. The performance test did not validate the learning model directly, but it did indicate suggest that the system is usable. In the third validated system [7], the authors set up experiments in which groups of students assembled a part of a computer; one group used Google to retrieve information and the other group used the LORAMS system to watch videos previously recorded by other students who had had the same learning experience earlier. The results suggest that LORAMS helped the students of the latter group perform better than the first group.

\section{Observation 3}

All except one of the reviewed systems use a clientserver architecture, and the exception implements a touchbased and RFID-enabled sensor board in a museum [5]. In this stand-alone system, the sensor board is directly connected to a computer which also manages the video projector used to project an image onto a board. The projected video is adapted to user actions and objects places on the board. Of the client-server based systems, two systems also allowed ad-hoc peer-to-peer communication without server intervention.

Details of hardware and software were not given in many of the reviewed papers and none presented a thorough technical description. Therefore, the following information may not correspond to all the state-of-the-art technologies used in pervasive learning environments. The operating systems of the mobile devices were Windows Mobile, Windows XP and Symbian OS. On the server side, XML was used for encapsulating data and messages. Furthermore, [13] used TRON (The Realtime Operating system Nucleus) operating system on the server. In other systems the operating system was not explicitly mentioned. Communication between the server and the client was established either by GPRS or WLAN, and two papers mentioned the usage of the HTTP protocol. The programming environment on the server side was mentioned only twice (Java Servlets on Tomcat software, and ASP.Net). Information about the programming language used on the client was available for all but seven of the systems, and were: C++ (3), Java (2), Visual Basic (2), C\# (1) and Flash (1). One of the systems used both Flash and $\mathrm{C}++$.

Mobile devices were used as learning tools in all but one of the systems. Explicitly mentioned types of mobile devices were Tablet PCs (2), PDAs (6) and mobile phones (3). Based on this information we can conclude that PDAs may be currently the most popular client type in pervasive learning environments. However, due to the recent convergence of mobile phones and PDA devices, both device types could be used for the same purpose. Tablet PCs are somewhat clumsy for pervasive learning in systems where high mobility is required. We established different roles of mobile devices based on the extracted information, and these roles are presented in table $\mathrm{V}$ together with their frequencies and descriptions. Frequency denotes how many times a role was present in the reviewed systems, and it is worth noticing that in one system a mobile device can have several roles, but none of the systems supported all five. One system used a mobile 
device as an auxiliary tool for reading RFID tags, but users were also able to use the system without a mobile device.

TABLE V.

Roles OF MOBILE DEVICES IN PERVASIVE LEARNING ENVIRONMENTS

\begin{tabular}{|l|l|l|}
\hline \multicolumn{1}{|c|}{$\begin{array}{c}\text { Role of a } \\
\text { mobile device }\end{array}$} & $\mathbf{f}$ & \multicolumn{1}{|c|}{ Description } \\
\hline $\begin{array}{l}\text { Data } \\
\text { collection tool }\end{array}$ & 5 & $\begin{array}{l}\text { Users collect data from the environment by using } \\
\text { information capturing features of the device such } \\
\text { as a camera (still and video images). Captured } \\
\text { data can be processed further by the system or } \\
\text { stored as a trace of learning activities, for } \\
\text { example. }\end{array}$ \\
\hline $\begin{array}{l}\text { Content } \\
\text { representation }\end{array}$ & 13 & $\begin{array}{l}\text { The high frequency indicates that this is probably } \\
\text { the most important role of mobile devices in } \\
\text { pervasive learning systems. In this role, mobile } \\
\text { devices are used to view context-sensitive content } \\
\text { provided by the system. The format of the } \\
\text { content represented on mobile devices in the } \\
\text { reviewed systems was text, image, audio or } \\
\text { video. }\end{array}$ \\
\hline $\begin{array}{l}\text { Communicatio } \\
\text { tool }\end{array}$ & 4 & $\begin{array}{l}\text { In some of the systems mobile devices were } \\
\text { utilised to establish communication between } \\
\text { users of the system. The forms of communication } \\
\text { are explained in Observation 4. }\end{array}$ \\
\hline $\begin{array}{l}\text { Navigation } \\
\text { tool }\end{array}$ & 2 & $\begin{array}{l}\text { Mobile devices were used for navigation; with } \\
\text { the help of the device a user is able to know } \\
\text { his/her own location or a location of a specific } \\
\text { object within the environment. In the reviewed } \\
\text { systems, the navigation feature was either based } \\
\text { on GPS or RFID. }\end{array}$ \\
\hline $\begin{array}{l}\text { In two systems, different types of announcements } \\
\text { and notices were delivered to users' mobile } \\
\text { devices, such as reminders and announcements } \\
\text { submitted by the teacher. }\end{array}$ \\
\hline
\end{tabular}

\section{Observation 4}

Most of the reviewed systems were built to support multiple users. We consider two different aspects of a multi-user system: the first aspect is support for multiple simultaneous users, and the second aspect is system mediation of communication between users. In other words, a system can support multiple simultaneous users without providing methods for communication, or it can support communication among users by some means. Twelve of the fifteen reviewed systems supported multiple simultaneous users, however, this data could not be extracted from all the papers. The number of systems providing communication tools for users was only six. Communication between users was either physical (2) or virtual (4). We considered as physical communication only those cases in which the communication by conversation or other physical means was explicitly mentioned as a part of the learning experience. Some of the systems allow both virtual and physical communication if the users share the same location and time. The systems providing tools for virtual communication utilised one or several of the following methods: forum, chat, SMS, instant messaging and content sharing. It is notable that none of the systems used audio or video communication even though particularly audio communication would be natural for mobile devices.

\section{E. Observation 5}

The roles of the physical environment had some variation but in general three different roles were recognisable, albeit not explicitly presented. These roles and their respective frequencies were: context for learning (9), content for learning (7), and system resource (3). It is worth noticing that in one system an environment can have multiple roles. For example, there were five cases where the environment was both context and content for learning. Additionally, two of the reviewed systems, an interactive sensor board for museums [5] and an interactive toy set for children [7], did not utilise the environment, and one paper did not state the role of the environment at all. Environment is a context for learning when learning is situation-based and the system adapts according to situations and contexts in which the user is present. This is also called contextual or situational learning. The environment provides content for learning when the system utilises the information within the environment as a learning resource. Finally, environment is a system resource when some objects within the environment are triggers for system events (e.g. furniture with embedded sensors which trigger usage events [2]). Fig. 1 depicts the central role of a physical environment in pervasive learning systems.

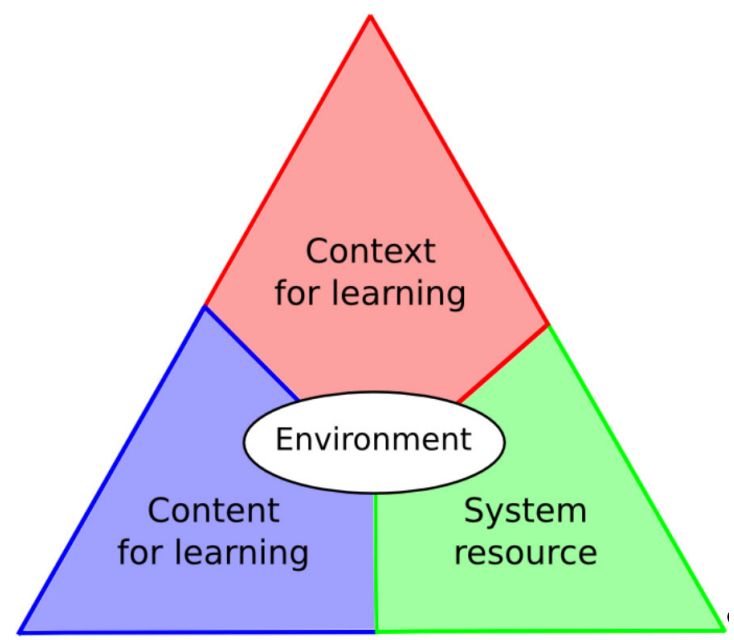

Figure 1. Three Roles of Physical Environment in Pervasive Learning Systems

\section{DISCUSSION}

The evidence presented in Observation 1 suggests that RFID is the most prevalent sensor technology used in pervasive learning environments, in part due relatively cheap price of RFID tags (approx. $1 €$ each in the authors' countries) and readers (150€), compared to the cost of a basic wireless sensor node of at least $300 €$. RFID-based readers are already available in some mobile devices as integrated chips, including models by Nokia and Samsung, and we expect that RFID will become a mainstream technology in mobile devices within 5 years. This development will enable tagging any object in a pervasive learning environment, thus making the underlying system more aware of the environment.

Observation 2 identifies several suitable learning models; however these require proper validation and comparison. Many of the proposed learning models were not validated, and those that were did not provide reliable 
results, as the test scenarios were inadequate in terms of the numbers of test participants and repetitions. It was discouraging to discover that only a handful of papers explicitly discussed learning models, and this leads us to believe that the authors of the other papers either did not consider learning models at all or did not include that information. All the learning models followed an informal constructivist approach. Authentic learning was mentioned more than once, thus suggesting its potentiality for pervasive learning. Nevertheless, the results of the observation 2 indicate that in this field learning model validations are required before any of the models can be seriously recommended.

Observation 3 concentrated on technical implementations of pervasive learning environments and roles of mobile devices in them. The use of client-server architectures in most of the systems shows that centralised control is used in preference to a distributed system. The benefits of using a centralised approach are the ease of installation and maintenance. However, a distributed system consisting of autonomous sensor nodes and one or more coordinating servers would be more fault-tolerant and load-balanced. Fault tolerance is particularly important in large systems which are running constantly and have hundreds or thousands of resources. The systems presented in the reviewed papers were quite small, thus the absence of distributed control is justified.

Popularity of PDA devices (6) as clients over Tablet PCs (2) and mobile phones (3) can be explained with screen size, physical dimensions, and processing capabilities. Displays on mobile phones are often too small for viewing information other than text and low quality images/video. On the other hand, Tablet PCs have large displays, but they are more difficult to carry around due to their large physical size. PDA devices often have larger displays than mobile phones and their size is smaller than that of Tablet PCs. Moreover, PDA devices have enough processing power for handling basic media types, while the resources are often more limited on mobile phones. Despite the popularity of PDA devices, mobile phone and PDA technologies have been converging, and there is a similar trend of convergence going on between laptops and mobile phones/PDAs. These new devices are called Ultra Mobile PCs (UMPCs) and their size is smaller than Tablet PCs, but bigger than mobile phones or PDAs. In addition to being highly portable, UMPC devices are capable of running a fullscale Windows XP operating system or equivalent Linux distribution, thus making them suitable client devices for various software solutions supporting pervasive learning activities. Currently the problems of UMPCs are high price and relatively short battery life. However, we can expect these aspects to improve in the near future.

According to observation 3 , there were five types of roles for mobile devices in the reviewed systems: data collection tool, content representation tool, communication tool, navigation tool and notice receiving tool. Since the content representation tool was the only role having a frequency more than 10, many of the systems merely concentrated on providing contextsensitive content to the user. This indicates that there is work to be done to increase interaction between the environment and the users, as well as among the users. For example, the data gathered with a data collection tool can be saved and processed later to continue the learning experience at another location, e.g. at home or in a classroom. As another example, communication with peers can help users to establish and strengthen social relationships.

Observation 4 concluded that only a few pervasive learning environments are truly multi-user systems through supporting communication among users. The lack of voice- and video-based communication was also noted, and we suggest that a reason may be the requirement for other running applications to be closed before using mobile phones' built-in voice call capabilities. Furthermore, creating a new reliable VoIP (Voice Over IP) application is not a trivial task. Audio/video-based communication is more personal, instant and effective than forums or chats. If a pervasive learning environment is to be built on a principle of virtual collaboration, using instant communication is possibly a good way to implement it. An alternative method is to provide a meeting request tool for the users through which two or more users could meet physically after agreeing on it virtually. This kind of approach was used by [6] where two users of the system met physically after one user had sent a help request to another user.

In Observation 5, we distinguished three different roles for the physical environment in pervasive learning systems: context for learning, content for learning and system resource, and the frequency figures $(9,7$ and 3 , respectively) indicate that context and content are used most often. Usage of the environment as a system resource would be higher if more systems would embed wireless sensor networking components for sensing different aspects of the environment. The low frequency of the system resource role is related to the lack of interaction with the environment; if the system would be able to closely observe user's behaviour and the state of the physical environment, the system would become more responsive and adaptive. This would in turn encourage users to interact more with the environment by using different objects and observing the consequences on the mobile device or in the physical environment.

\section{CONCLUSIONS}

We have reviewed 15 pervasive learning environments by concentrating on their underlying technology, suitable learning models, and roles of mobile devices. From the technological perspective, the majority of the systems used client-server architectures using mobile device clients, suggesting centralised control. The most popular client mobile devices were PDAs, and RFID was the most used sensor technology, partly due to its cheap cost compared to other sensor types. The most popular roles of the mobile devices were as a content representation tool and a data collection tool. We concluded that there is still work to be done in order to utilise the capacity of mobile devices to the full extent. Three different roles for the physical environment were identified: context for learning, content for learning, and system resource. From the point of view of learning models, the reviewed systems implicitly or explicitly suggested several constructivist models to be suitable for pervasive learning environments, in which authentic context is in a central position. However, the suggested learning models were insufficiently validated, and this is an area for future investigation. 
As a future activity, we intend to use the results of this survey to design and build a flexible pervasive mobile learning environment that uses not only RFID, but also wireless sensor nodes, auxiliary input/output devices, mobile devices and intelligent agents. We will build this system modularly in a way that will be easy to adapt to different environments such as museums, schools, fairs, amusement parks, art houses and companies. We will use the system to investigate how different learning models can be efficiently applied in pervasive learning environments and what are the critical features of such environments.

\section{REFERENCES}

[1] D. Barbosa, A. Yamom, I. Augustin, L. da Silva, C. Séller, and J.Barbosa, "Learning in a large-scale pervasive environment," Proc. of the Pervasive Computing and Communications Workshop, 2006.

[2] J.S. Beaudin, S.S. Intille, E. Munguia Tapia, R. Rockinson, and M.E. Morris, "Context-sensitive microlearning of foreign language vocabulary on a mobile device,” Proc. of the European Conference on Ambient Intelligence 2007.

[3] M. Derntl, and K.A. Hummel, "Modeling context-aware elearning scenarios," Proc. of the Third International Workshop on Pervasive E-Learning, 2005.

[4] P. Grew, F. Giudici, and E. Pagani, "Specification of a functional architecture for e-learning supported by wireless technologies," Proc. of the Pervasive Computing and Communications Workshop 2006.

[5] F. Kusunoki, M. Sugimoto, and H. Hashizume, "Toward an interactive museum guide system with sensing and wireless network technologies," Proc. of the IEEE International Workshop on Wireless and Mobile Technologies in Education 2002.

[6] T.H. Laine, C. Islas Sedano, M. Vinni, and E. Sutinen, "Engagement, motivation and inspiration: The SciMyst Framework in Museums," Proc. of the Fourth Conference on New Exploratory Technologies, 2007.

[7] M. Lampe,and S. Hinske, "Integrating interactive learning experiences into augmented toy environments," Proc. of the Pervasive Learning Workshop at the Pervasive 2007 Conference.

[8] K. Mitchell, and N.J.P. Race, "uLearn: facilitating ubiquitous learning through camera equipped mobile phones, ” Proc. of the Third IEEE International Workshop on Wireless, Mobile and Ubiquitous Technologies in Education, 2005.
[9] H. Ogata, Y. Matsuka, M. El-Bishouty, and Y. Yano, "LORAMS: capturing sharing and reusing experiences by linking physical objects and videos," Proc. of the Pervasive Learning Workshop at the Pervasive 2007 Conference.

[10] H. Ogata, and Y. Yano, "Context-aware support for computersupported ubiquitous learning," Proc. of the Second IEEE International Workshop on Wireless and Mobile Technologies in Education, 2004.

[11] H. Ogata, and Y. Yano, "Knowledge awareness map for computer-supported ubiquitous language-learning,” Proc. of the Second IEEE International Workshop on Wireless and Mobile Technologies in Education, 2004.

[12] H. Ogata, C. Yin, and Y. Yano, "JAMIOLAS: supporting Japanese mimicry and onomatopoeia learning with sensors," Proc. of the Fourth IEEE International Workshop on Wireless, Mobile and Ubiquitous Technologies in Education, 2006.

[13] K. Sakamura, and N. Koshizuka, "Ubiquitous computing technologies for ubiquitous learning," Proc. of the Third IEEE International Workshop on Wireless, Mobile and Ubiquitous Technologies in Education, 2005.

[14] E. Syukur, and S.W. Loke, "MHS learning services for pervasive campus environment," Proc. of the Fifth International Workshop on Pervasive E-Learning, 2007.

[15] A. Syvänen, R. Beale, M. Sharples, M. Ahonen, and M. Lonsdale, "Supporting pervasive learning environments: adaptability and context awareness in mobile learning,” Proc. of the 2005 IEEE International Workshop on Wireless and Mobile Technologies in Education.

[16] M.J. Weal, D. Cruickshank, D.T. Michaelides, D.E. Millard, D.C. De Roure, K. Howland, and G. Fitzpatrick, "A card based metaphor for organising pervasive educational experiences," Proc. of the Pervasive Computing and Communications Workshop 2007, pp. 165-170.

\section{AUTHORS}

T.H. Laine is with the Educational Technology research group at the Department of Computer Science and Statistics at University of Joensuu, Finland (e-mail: thlaine@cs.joensuu.fi).

M. Joy is with the University of Warwick/Computer Science, Coventry, UK (e-mail: m.s.joy@warwick.ac.uk). Manuscript received 6 October 2008. Published as submitted by the authors. 